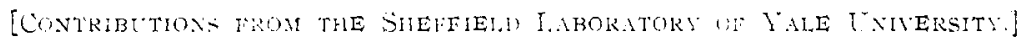

\title{
RESEARCHES ON PYRIMIDINES: SYNTHESIS OF URACIL-3-ACETIC ACID.
}

[THIRTY-FIRST P.APER.]

BY IIENKY L. WHEELER AND I.EONARD M. TIDDLE.

Received May s, rgos.

Johnson and Heyl found when methyl iodide and 2-ethylmercapto-6oxypyrimidine (formula I) are warmed in alcoholic solution in the presence of potassium hydroxide, that the methyl group substitutes in the I-position of the pyrimidine and that 1-methyl-2-ethylmercapto-6-oxypyrimidine, II, results. ${ }^{1}$ The formation of a 3 -nethyl derivative has not yet been observed in this reaction. When the mercapto derivative was warmed with hydrochloric acid, I-methyl uracil, III, was obtained. The structure of this methyl uracil was settled by converting it into $\mathrm{I}$-methyl5-nitro-6-oxypyrimidine which had been obtained previously, in a different manner by Behrend and Thurm. ${ }^{2}$

We have obtained an entirely different result when 2-ethylmercapto6-oxypyrimidine is treated with ethyl chloracetate and alkali in alcoholic solution. The alkylation in this case, although under similar conditions, takes place in the 3-position and 2-ethylmercapto-6-oxypyrimidine-3-ethyl acetate, $I V$, is formed.

When this ester is warmed with alkali it dissolves and hydrochloric acid then precipitates 2-ethylmercapto-6-oxypyrimidine-3-acetic acid, $V$. If this acid is warmed with hydrochloric acid, mercaptan is evolved and uracil-3-acetic acid results, VI.

The mercapto acid, $V$, was also obtained by heating 2-ethylmercapto6-oxypyrimidine in alkaline solution with potassium chloracetate and uracil-3-acetic acid can be directly prepared by treating uracil in alkaline solution with chloracetic acid At this point it seemed possible that alkyl iodides might be found to regularly give I-alkyl derivatives. We therefore examined the action of ethyliodoacetate on uracil and it was found that this gave the same acid as the chlorine compound.

It is evident from these results that the structure of each new alkyl derivative must be determined separately and uracil-3-acetic acid should be of service in this direction. ${ }^{3}$ The proof of the structure of the acetic acid compounds was obtained as follows: Johnson and Heyl's I-methyluracil, III, was treated with chloracetic acid and an excess of alkali;

'THIS JOLRNAL, 37, 628 (1907'.

2. Amn, (Liebig), 323, I60.

"The above results also show that alkylation does not give any clue to the position of hydrogen in the substance alkylated. Since 2-ethyl-mercapto-6-oxypyrimidine is soluble in alkali it is represented as having the $\mathrm{NH}-\mathrm{CO}$ group with hydrogen in the I-position. 
this gave I-methyluracil-3-acetic acid, VII, and the same methyl acid was formed when our uracil acetic acid, VI, was methylated with methyl iodide and potassium hydroxide in methyl alcohol. The structure of these compounds and their relations are expressed in the following formulas:

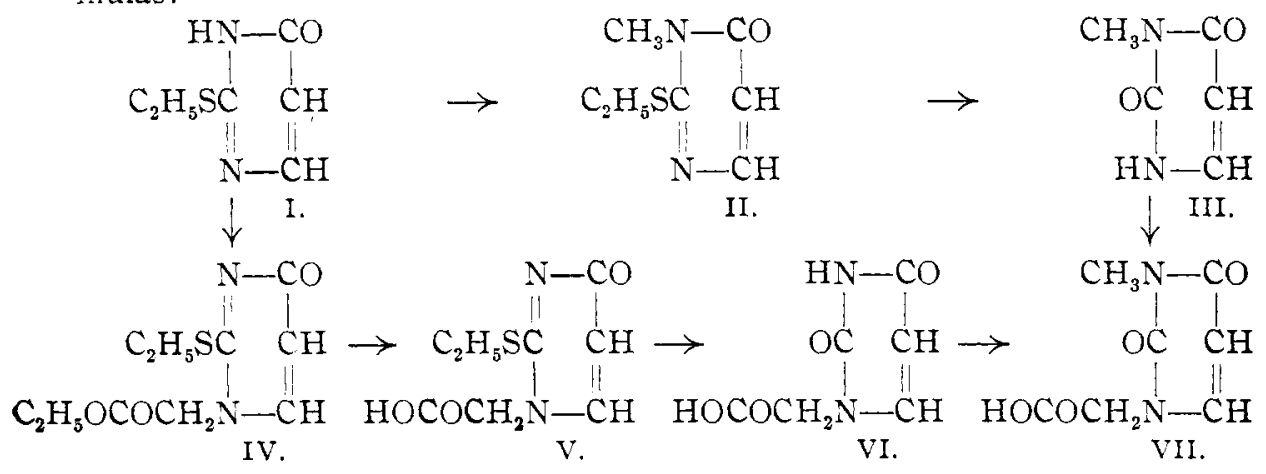

Experimental Part.

2-Ethylmercapto-6-oxypyrimidine-3-ethyl Acetate (formula IV, above). Molecular proportions of sodium, 2-ethylmercapto-6-oxypyrimidine and ethylchloracetate were dissolved in alcohol, in the order named, and the mixture was warmed until it no longer gave an alkaline reaction (2-3 hours). The solution, filtered from sodium chloride, gave a thick oil on evaporating to dryness. When this was shaken with ether and water it deposited prismatic crystals. The material was crystallized from water; 5 grams dissolved in about $20 \mathrm{cc}$. of hot water and on cooling bunches of beautiful, long, colorless prisms separated which melted to a clear oil, without effervescence, at $129^{\circ}$. Analysis:

Calculated for $\mathrm{C}_{10} \mathrm{H}_{14} \mathrm{O}_{3} \mathrm{~N}_{2} \mathrm{~S} ; \mathrm{N}_{2}$ Ir.57; found, Ir.87.

This ester is readily soluble in alcohol and in dilute alkali.

2-Ethylmercapto-6-oxypyrimidine-3-acetic Acid (formula V).-The solution of the above ester in dilute alkali gave no precipitate when acidified with acetic acid. On adding hydrochloric acid in slight excess a granular precipitate was formed. This was found to be very soluble in hot alcohol and moderately so in cold. It is difficultly soluble in water. The long, slender prisms from alcohol had a fern-like growth and melted at $208-209^{\circ}$ with some effervescence.

Calculated for $\mathrm{C}_{8} \mathrm{H}_{10} \mathrm{O}_{3} \mathrm{~N}_{2} \mathrm{~S}: \mathrm{N}, \mathrm{I3} 3.08$; found, 13.12 .

Five grams of 2-ethylmercapto-6-oxypyrimidine were dissolved in two molecular proportions ( 3.6 grams) of potassium hydroxide and three grams of chloracetic acid in $5 \mathrm{cc}$. of water were added. When this solution was evaporated nearly to dryness on the steam bath, I.5 grams of unaltered 2-ethylmercapto-6-oxypyrimidine separated. The solution 
was filtered, made alkaline with sodium hydroxide and reheated a short time on the steam bath. On cooling and adding hydrochloric acid 3. I grams of the above mercapto acid were obtained. When this material was warmed with strong hydrochloric acid, on the steam bath, mercaptan was evolved and uracil-3-acetic acid was obtained.

Lracil-3-acetic Acid (formula V1),-.The above mercapto acid and ester are quantitatively converted into uracil-3-acetic acid by means of hydrochloric acid. It was found, however that uracil-3-acetic acid conld be more conveniently prepared directly from uracil as follows: An aqueous solution of uracil ( 10.2 grams) in two molecular proportions of potassium hydroxide was boiled with the calculated quantity of chloracetic acid. When the solution gave an acid reaction it was made alkaline by the addition of a few drops of potassium hydroxide. When it finally remained alkaline after ro minutes boiling, it was cooled and acidified with hydrochloric acid. 'lhe yield of uracil-3-acetic acid (ro.8 grams) was 70 per cent. of the theoretical. The acid was readily soluble in hot water and moderately soluble in cold. It formed small blocks or tables which melted with effervescence at $285^{\circ}$. It was nearly insoluble in methyl or ethyl alcohol.

Calculated for $\mathrm{C}_{6} \mathrm{H}_{6} \mathrm{O}_{4} \mathrm{~N}_{2}: \mathrm{N}, 16.47$; found, $16.57, \mathrm{I} 6.69$.

This acid showed no tendency to form a hydantoin. It was found to be very stable when heated with acids. It was obtained unaltered when boiled for Io hours with hydrochloric acid. It dissolved in boiling acetic anhydride and on evaporating and crystallizing the residue from 85 per cent. alcohol, or water, unaltered acid was obtained. It was also obtained unaltered when heated with 20 per cent. sulphuric acid for one and a half hours at $200^{\circ}$. It gave no color with bromine water and barium hydroxide.

The potassinm salt of uracil-3-acetic acid, prepared by dissolving the acid in the calculated quantity of potassium hydroxide, crystallized in long, flat prisms which were very soluble in cold water.

The copper salt was obtained as a minutely crystalline light blue salt on mixing a solution of the potassium salt with one of copper sulphate. Silver and zinc sulphates also gave crystalline salts while the precipitates obtained with mercuric chloride and lead acetate were amorphous.

The barium salt obtained by dissolring the acid in a solution of barium hydroxide and then remoring the excess of barium by carbon dioxide and concentrating, formed balls of needles like uracil. It was readily soluble in hot water. It was not decomposed by acetic acid. 
Uracil-3-methylacetate,

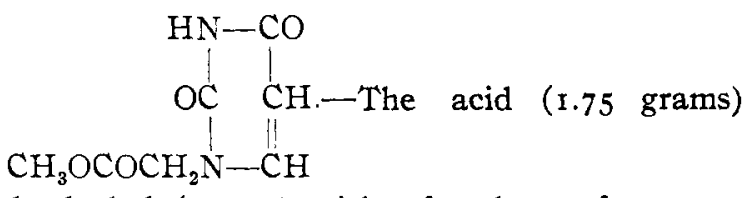

was esterified in methyl alcohol ( $50 \mathrm{cc}$.) with a few drops of concentrated sulphuric acid. On evaporating to about is cc. and cooling, I.2 grams or 63 per cent. of the ester separated. It was readily soluble in hot water and hot alcohol. It formed beautiful color. less needles and although it was repeatedly crystallized from water it melted as if it was a mixture, partially melting at about $177^{\circ}$, then melting to a clear oil at about $216^{\circ}$. Its appearance and the following nitrogen determination indicated that it was pure.

Calculated for $\mathrm{C}_{7} \mathrm{H}_{8} \mathrm{O}_{4} \mathrm{~N}_{2}: \mathrm{N}$, I5.29; found, 15.13 .

5-Bromuracil-3-acetic Acid,

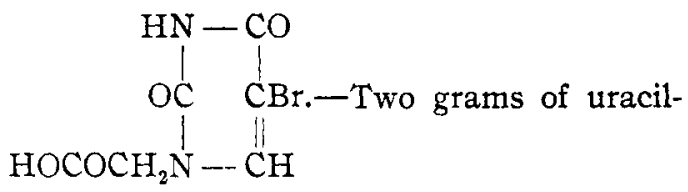

3 -acetic acid dissolved in water were treated with an excess of bromine and the solution was then allowed to evaporate in the air. On drying the residue over sulphuric acid, it weighed 2.8 grams or 96 per cent. of the calculated yield for a monobrom substitution product. It was readily soluble in hot water, difficultly so in cold and nearly insoluble in alcohol. It formed bunches of colorless needles which melted with effervescence at $244^{\circ}$.

Calculated for $\mathrm{C}_{6} \mathrm{H}_{8} \mathrm{O}_{4} \mathrm{~N}_{2} \mathrm{Br}$ : N, II.24; found, I1.58.

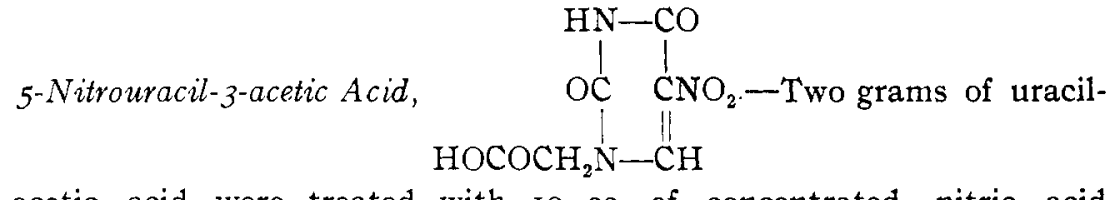

3-acetic acid were treated with ro cc. of concentrated nitric acid and $5 \mathrm{cc}$. of concentrated sulphuric acid on the steam bath. In twenty minutes a crop of colorless crystals had separated, weighing 1.75 grams or 70 per cent. of the calculated amount. This material was readily soluble in hot water and difficultly soluble in alcohol. It formed colorless prisms which melted with effervescence at $264-265^{\circ}$.

Calculated for $\mathrm{C}_{6} \mathrm{H}_{5} \mathrm{O}_{6} \mathrm{~N}_{3}: \mathrm{N}$, 19.55; found, 19.66, 19.28.

I-Methyluracil-3-acetic Acid,

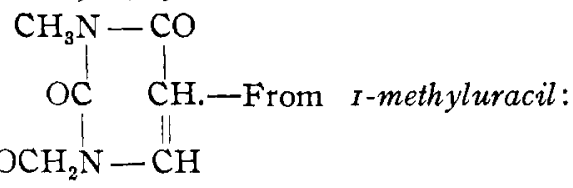

A mixture of 2.6 grams methyl uracil, 3 grams of chloracetic acid 
and 3.2 grams of potassium hydroxide in $20 \mathrm{cc}$. of water were warmed on the steam bath. In a half hour the solution was acid to litmus. It was made alkaline and boiled for a short time. On acidifying the solution with hydrochloric acid and cooling, crystals separated; this material weighed 2.7 grams. It crystallized from water in needle-like prisms or in prismatic plates, and melted constantly at $239^{\circ}-240^{\circ}$ to a clear oil without effervescence. It forms beautiful, transparent prisms from alcohol.

Analysis $\mathrm{I}$.

From Lracil-3-acetic Acid: Uracil acetic acid (1.2 grams) and four molecular proportions of potassium hydroxide were dissolved in a little water. An excess of methyl iodide ( 5 grams) was added and sufficient methyl alcohol to effect solution. The mixture was allowed to stand in a warm place for two days when the solution was acid to litmus. It was evaporated to dryness and the residue was crystallized from water containing a little sulphur dioxide. This gave 0.6 gram of material crystallizing in thin prismatic plates and having properties identical with the acid from I-methyl uracil. When these substances were mixed, the melting point was not lowered. Analysis II.

Calculated for $\mathrm{C}_{7} \mathrm{H}_{8}()_{4} \mathrm{~N}_{2}: \mathrm{X}, 15.21$; found: I, $15.18 ; 1 \mathrm{I}, 15.41$

NeW Havex, Conx., May, goo.

[CONTRIBITIONS FROM THE SHEFFIELD IABORATORY OF Y'ALE UNIVERSITY]

\title{
RESEARCHES ON PYRIMIDINES: SYNTHESIS OF URACIL-4-ACETIC ACID.
}

\author{
[THIRTY-SECOND PAPER.] \\ BY HENRY L. WHEELER AND LEONARD M. I,IDDLE. \\ Received May 8, 1908.
}

Pinner has shown that acetone dicarboxylic ester condenses with benzamidine giving phenyloxypyrimidine acetic ester. ${ }^{1}$ He also found that the ester condenses with other aromatic amidines of the general formula, $\mathrm{R}-\mathrm{C}\left(\mathrm{NH}_{2}\right) \mathrm{NH}$. Acetamidine and phenylacetamidine, he states did not give crystalline products.

The pseudothioureas may be viewed as amidines derived from the iminothiocarbonic esters. 2-Ethylpseudothiourea is ethylthiocarbamidine or mercaptoformamidine:

$$
\mathrm{C}_{2} \mathrm{H}_{5} \mathrm{~S}-\mathrm{C}(\mathrm{OR}) \mathrm{NH} \rightarrow \mathrm{C}_{2} \mathrm{H}_{5} \mathrm{~S}-\mathrm{C}\left(\mathrm{NH}_{2}\right) \mathrm{NH} \text {. }
$$

In accordance with this we have found that 2-ethylpseudothiourea condenses very smoothly, in alkaline solution, with acetonediethylcarboxylate, yielding 2-ethylmercapto-6-oxypyrimidine-4-ethyl acetate (I). The condensation may be represented as follows:

$$
{ }^{1} \text { Ber., 28, 480 (1895). }
$$

